\title{
Breakage mechanisms of highly porous particles in 1D compression revealed by $\mathrm{X}$-ray tomography
}

\author{
G. GUIDA*, F. CASINI†, G. M. B. VIGGIANI†, E. ANDÒ§ and G. VIGGIANI\|
}

\begin{abstract}
Grain breakage affects a number of geotechnical engineering problems. In this research study, the breakage of an artificial, porous granular material (light-expanded clay aggregate (LECA)) has been studied in one-dimensional compression with both standard laboratory techniques and in situ X-ray tomography during loading. X-ray tomography has revealed that there is a wide distribution of internal porosity among LECA particles, and particle tracking has been used, for the first time, to give an objective measurement of each particle's life expectancy. Links between micro- and macro-scale quantities are discussed.
\end{abstract}

KEYWORDS: compressibility; in situ testing; particle crushing/crushability

ICE Publishing: all rights reserved

\section{INTRODUCTION}

In a number of geotechnical engineering problems, soil particles may break, implying significant changes of volume, strength, hydraulic conductivity and so forth, for the material. For example, breakage phenomena have been reported in pile foundations (Yusufuku \& Hyde, 1995; Kuwajima et al., 2009; Yang et al., 2010; Zhang et al., 2013) and in dams (Alonso et al., 2005). Particle breakage is traditionally characterised with average measurements at the sample scale of the evolution of the grain-size distribution (GSD) (Hardin, 1985; Einav, 2007; Casini et al., 2013; Guida et al., 2016), the effects on compressibility in oedometric tests (Altuhafi \& Coop, 2011; Altuhafi et al., 2016) and the effects on strength and dilatancy in shearing (Colliat-Dangus et al., 1988; Coop et al., 2004). On a radically different scale, several more recent contributions have characterised the micro-mechanics of particle breakage in systems composed of one or few particles (McDowell \& Bolton, 1998; Antonyuk et al., 2005; Cli \& Alshibli, 2012; Zhao et al., 2015; Todisco et al., 2017). Experimental work which bridges the gap between particle-scale breakage and sample-scale measurements is technically challenging given the number of particles required. X-ray tomography is a very well-suited non-destructive measurement tool for this kind of study, used with good results in sand (Cil \& Alshibli, 2014; Karatza et al., 2018; Okubadejo et al., 2017). This paper provides a further contribution for bridging this gap for the significantly more complex scenario of highly porous particles, which can be heavily prone to fracturing, followed by volumetric collapse. An artificial, porous

Manuscript received 28 February 2018; first decision 28 May 2018; accepted 28 May 2018.

Published online at www.geotechniqueletters.com on 29 June 2018.

*Università Niccoló Cusano, Rome, Italy

(Orcid:0000-0003-1129-7906).

†Università degli Studi di Tor Vergata, Rome, Italy

(Orcid:0000-0001-7933-9055).

†University of Cambridge, formerly Università degli Studi di Tor

Vergata, Rome, Italy (Orcid:0000-0002-0993-0322).

\&aboratoire 3RS, Grenoble, France

(Orcid:0000-0001-5509-5287).

|Laboratoire 3RS, Grenoble, France

(Orcid:0000-0002-2609-6077). granular material was studied on one-dimensional (1D) (oedometer) compression paths with traditional particle-size distribution measurements made on different samples after different maximum applied stresses. In addition, a 1D compression test was performed in situ inside a micro-focus X-ray tomography set-up, allowing particle-scale phenomena to be tracked throughout compression. The combination of these two experimental campaigns allows an original contribution to a 'micro-to-macro' analysis by relating averaged stresses and strains, particle-size evolution and micro-scale variables.

\section{DESCRIPTION OF THE MATERIAL}

The material studied is a light-expanded clay aggregate (LECA) provided by Laterlite SpA (2017). It is an industrial porous granular material used in a number of civil engineering applications due to its low density and thermal isolation properties. Compared to sand grains, LECA particles break at relatively low stress levels (Casini et al., 2013; Guida et al., 2016). LECA material can be a model material for some aspects of carbonate sands or pyroclastic rocks (e.g. intraparticle porosity, low density). Figure 1 shows X-ray image slices of LECA, whose geometry is $10.75 \mu \mathrm{m} / \mathrm{px}$ and are very heterogeneous in nature (Fig. 1(a)) and two zooms show highly porous particles (Fig. 1(b)) and non-porous particles (Fig. 1(c)).

\section{OEDOMETER TESTS}

The experimental campaign consisted of ten oedometer tests (lab tests), without X-ray scanning, all starting from the same conditions in terms of void ratio and GSD. Each test was stopped at a different value of maximum axial stress after which the GSD was measured destructively. In addition, a single oedometer compression test was performed in situ in the X-ray micro-tomography scanner in Laboratoire 3SR (tomo test), scanning the sample at the same stress levels for which GSDs were measured for the ten oedometer laboratory tests.

The oedometer cell of the lab tests is a steel thick cylinder with a reduced section of $25 \mathrm{~mm}$, in order to reach higher values of axial stress. The cell used in the tomo test - which is a cylinder closed at one end - is designed specifically with $\mathrm{X}$-ray scanning in mind, and thus is of reduced dimensions 


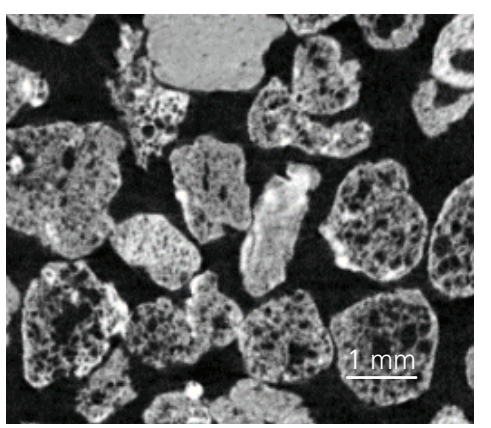

(a)

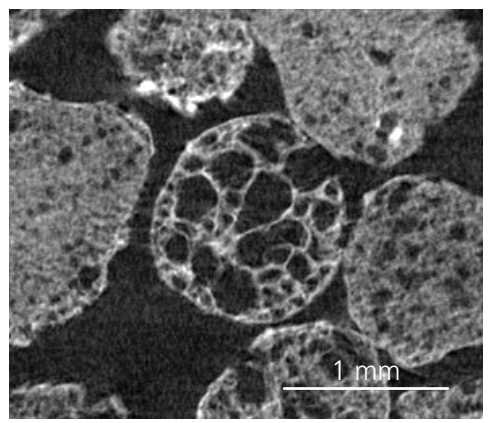

(b)

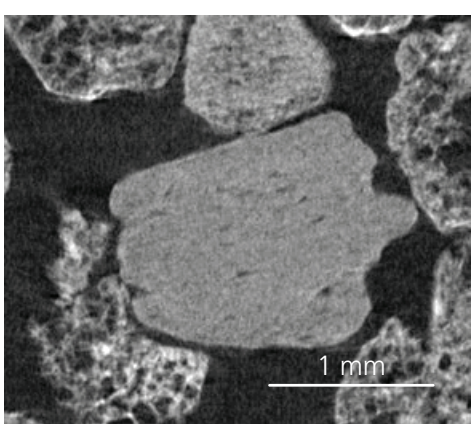

(c)

Fig. 1. (a) X-ray image slice; detail of (b) a highly porous particle and (c) a non-porous particle of LECA

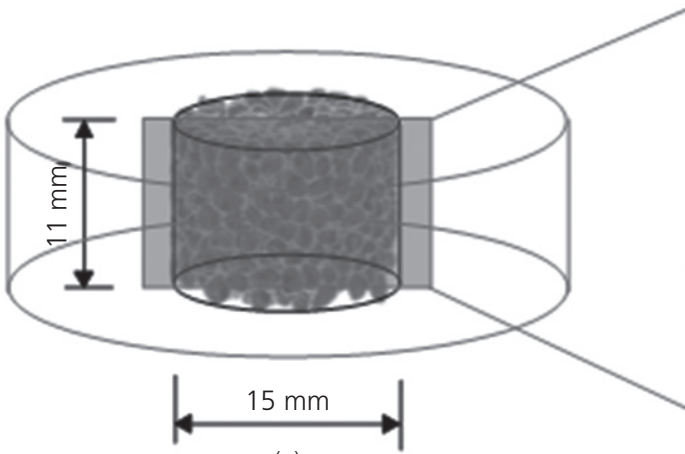

(a)

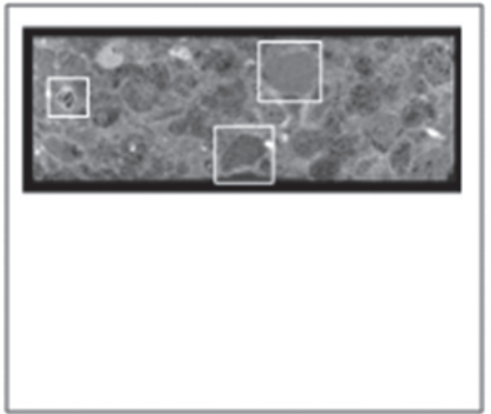

(d)

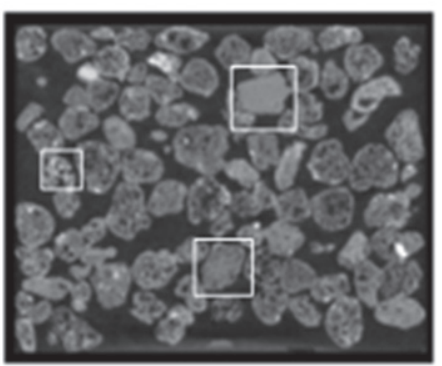

(b) $\rfloor$

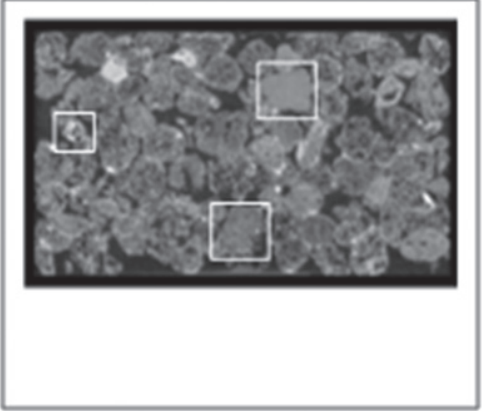

(c)

Fig. 2. Test set-up and results: (a) 3D sample reconstruction; (b-d) vertical slices increasing loading stages. Three particles surviving throughout the entire compression are identified

compared to conventional oedometers (internal diameter of $15 \mathrm{~mm}$ ) so that the entire specimen can be imaged at high resolution. To further facilitate X-ray scanning, Polyether ether ketone (PEEK) is selected as the material for the cell due to its low X-ray attenuation, low friction and acceptable stiffness. To help minimise the deformation of the cell, a relatively large wall thickness of $20 \mathrm{~mm}$ is used.

The specimens were prepared using dry pluviation, aiming a dry mass of $8 \mathrm{~g}$ (lab tests) or $1 \mathrm{~g}$ (tomo test), obtaining heights of, respectively, $\sim 34$ or $\sim 11 \mathrm{~mm}$, making the sample loose $\left(e_{0}=4 \cdot 7\right)$.

The tests were conducted under displacement control with a constant rate of $1.00 \mathrm{~mm} / \mathrm{min}$ (lab tests) or the maximum reachable in the tomography device of $0.15 \mathrm{~mm} / \mathrm{min}$ (tomo test) up to the target axial stress. For the test with X-ray tomography an initial scan was done prior to loading. Thereafter, at each target stress the loading was stopped, and the sample was left to relax before performing an X-ray tomography scan.

Figure 2 shows a three-dimensional (3D) rendering of the sample in a sketch of the oedometric cell which is out of the field of view (Fig. 2(a)). Vertical slices at different stress levels, $\sigma_{\mathrm{a}}=0 \cdot 15 \mathrm{MPa}$ (Fig. 2(b)), $\sigma_{\mathrm{a}}=6 \mathrm{MPa}$ (Fig. 2(c)) and $\sigma_{\mathrm{a}}=36 \mathrm{MPa}$ (Fig. 2(d)) are also presented. The first vertical slice immediately shows that scans have been performed at a sufficient resolution to distinguish individual particles, as well as some internal porosity. Internal porosity varies significantly from one particle to another - some highly porous particles can be seen as well as some with practically no internal porosity. Some denser inclusions, showing as light grey and white in the image, can also be noted. The loose initial state is also visible from this slice. Note that, since this is a section through space, particles which appear to be floating obviously are supported by contacts elsewhere in space.

As loading progresses, Fig. 2(c) (6 MPa axial stress) reveals a large amount of axial shortening that appears to be due principally to a reduction of inter-particle porosity as particles rearrange. Figure 2(d) (36 MPa) reveals a further very large axial shortening, which now is clearly due to a decrease of both inter- and intra-particle porosity due to the breakage of a large number of particles. 


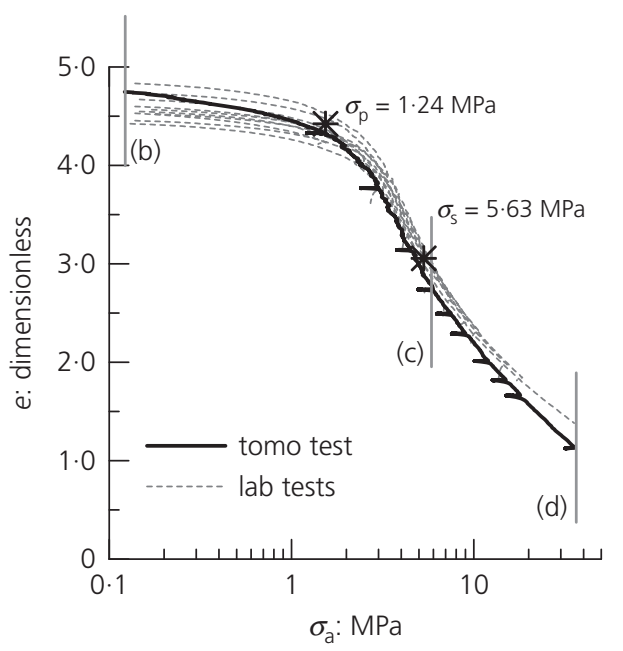

(a)

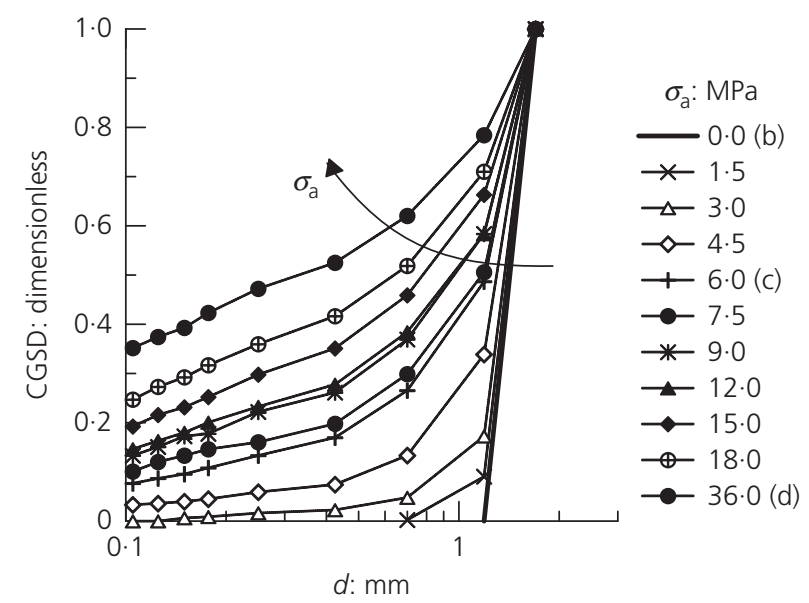

(b)

Fig. 3. (a) Compressibility curves (note the stress relaxations at the times when loading is stopped for X-ray scanning); (b) evolution of grading curve with stress (from the ten lab tests). CGSD, cumulative grain size distribution

Figure 3(a) reports the mechanical response in the void ratio - logarithm of axial stress $\left(e-\log \sigma_{\mathrm{a}}\right)$ plane. The response measured in the test with in situ scanning (tomo test) is in agreement with the behaviour observed in the laboratory (lab tests), even though there are some differences in the experimental set-up, namely the oedometer cell (material and size) and loading rate. The initial void ratio is very high $\left(e_{0}=4 \cdot 76\right)$, compared to typical sands, since it takes into account the presence of particle pores (intra-porosity), and because LECA has an extremely open configuration due to the surface complexity of its particles. Void ratio $e$, or the ratio between the volume of voids $V_{\mathrm{v}}$ over the volume of solids $V_{\mathrm{s}}$, includes intra-porosity because $V_{\mathrm{v}}$ is evaluated subtracting to the sample total volume $V$ only the volume of the solid phase $V_{\mathrm{S}}$ (evaluated by the weight and the density of the sample). The compressibility curve has a typical sigmoid shape with two characteristic points: the yield stress $\sigma_{\mathrm{p}} \approx 1.24 \mathrm{MPa}$, which marks the beginning of breakage, and the stress corresponding to the point of inflection $\sigma_{\mathrm{s}} \approx 5.63 \mathrm{MPa}$, which may correspond to an accumulation of fines without internal porosity - that is, material de-structuration. Finally, Fig. 3(b) shows the evolution of the grading curve, obtained by sieving at the end of each lab test. The original grading is very uniform, with a mean grain size $D_{50}=1.45 \mathrm{~mm}$ and a coefficient of uniformity of $1 \cdot 20$. The grading evolves by incremental clockwise rotations around the maximum diameter, finally reaching a very well-graded GSD $\left(D_{50}=0.34 \mathrm{~mm}\right.$ with the $45 \%$ of passing by weight at the sieve size $D=0 \cdot 105 \mathrm{~mm}$ ). Some particles possibly because they become cushioned by finer fragments of already broken particles - continue to survive at high pressures. Such surviving particles can be seen in Fig. 2(d).

\section{IMAGE PROCESSING}

The tomo test is accompanied by $3 \mathrm{D} \mathrm{X}$-ray attenuation field measurements repeated under different loads. This provides the possibility of significant micro-scale insight into particle-scale processes occurring throughout the test.

At least initially, the system studied is a granular one, with clearly visible particles (Fig. 2(b)). Making measurements of individual particle breakage under load depends critically on the identification of intact particles before the application of load, and on their tracking throughout the application of load.

Classic particle identification algorithms, such as those using marker-based watershed segmentation, cannot be used directly on these images, since the presence of pores inside grains heavily distorts the distance map on which the technique is based. The application of a threshold to select the solid phase for separation into individual particles clearly reveals this internal porosity (Fig. 4(a)). Internal

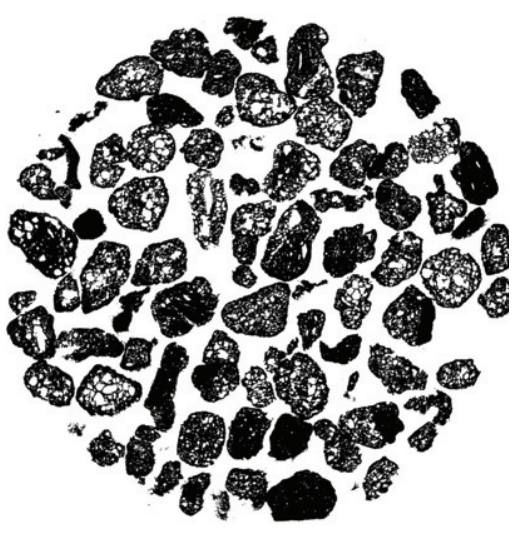

(a)

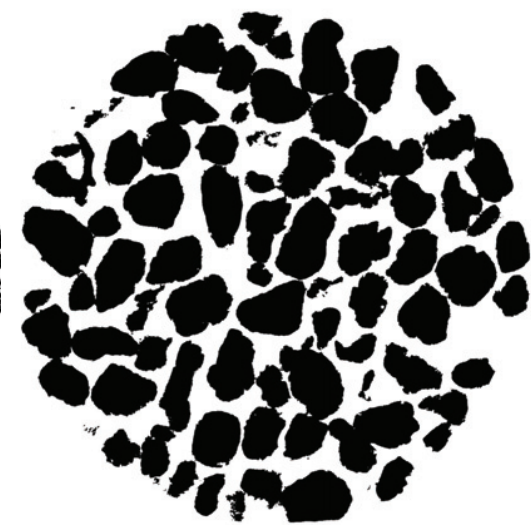

(b)

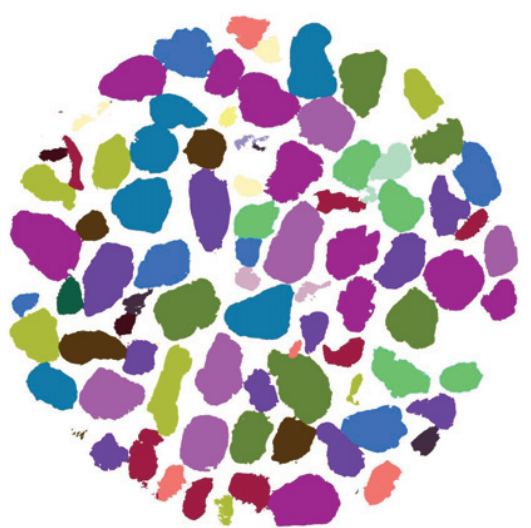

(c)

Fig. 4. Steps in grain identification: (a) binarisation; (b) filling holes; (c) labelling 


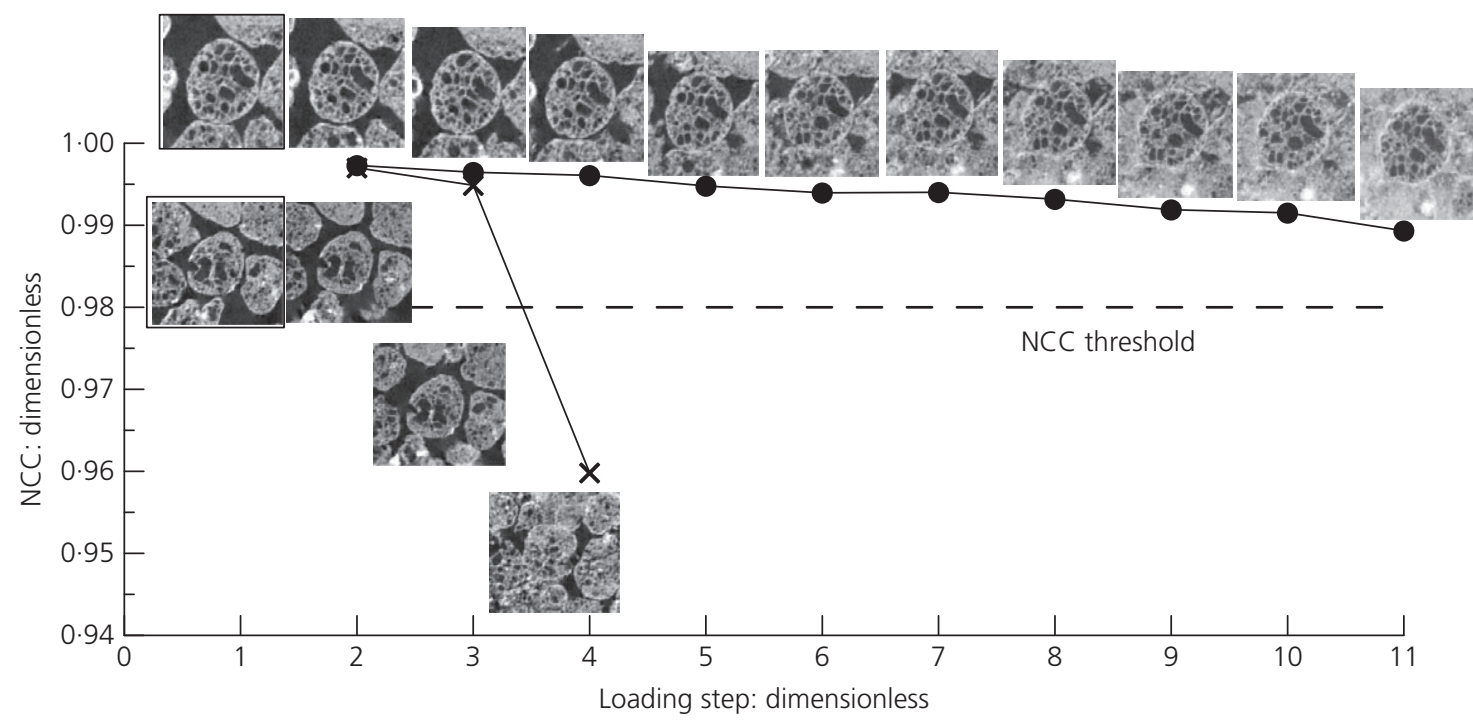

Fig. 5. NCC evolution for one 'surviving' and one 'breaking' particle. Images highlighted at the loading step 1 are the reference images

porosity is therefore virtually 'filled' (Fig. 4(b)), which then allows watershed segmentation to be performed successfully, yielding an image where each particle is individually labelled (Fig. 4(c)). The virtual filling is complicated by the fact that several intra-particle pores are connected to the outside. Those not connected to the outside are detected with a simple 'fill holes' and added back to the solid phase. Thereafter, pores connected to the outside are closed by 'dilating' the solid phase and then detected by 'fill holes'; finally, the pores volume is restored with a dilation and then added back to the original solid phase. This is repeated for three levels of dilation. This labelled image is only created for the first loading step.

Starting from this labelled image, particles are tracked using discrete digital image/volume correlation, a correlation technique particularly suited for tracking grains with non-spherical shapes (Hall et al., 2010; Andò et al., 2012). In this family of techniques, the zone in which the similarity is computed between the two image sub-volumes (e.g. insets in Fig. 5) is limited to the volume defined in the reference images by the label of each grain (e.g. Fig. 4(c)).

Discrete digital image correlation (DIC) is always performed starting from the labelled configuration (the initial unstressed state) using TomoWarp 2 (Tudisco et al., 2017). The measured kinematics of each grain is systematically used as an initial guess for the next step. Given the degree to which some particles are destroyed by the end of the test (Fig. 2(d)), it is clear that these particles cannot be tracked all the way to the end of loading. The degree to which the image of a particle in a deformed step matches the initial configuration is measured in the code by a normalised correlation coefficient (NCC) (Lewis, 1995), which is exactly 1 for a perfect match, and less than 1 as the quality of the match decreases. In this work, the authors make the hypothesis that particles can either undergo rigid-body motion or break. Since the former can be captured with discrete DIC, then any failure to correlate is ascribed to the occurrence of the latter. They adopt a threshold value of $\mathrm{NCC}=0.98$ to separate intact particles from broken ones, as described in Karatza (2017). Particles that fall below the threshold are not tracked further.

Figure 5 shows the trend of NCC for two particles throughout loading: the 'surviving' particle always has a value of NCC above the threshold and so is deemed not to break while the 'breaking' particle has a sudden drop of NCC in step 4, which is associated to breakage.

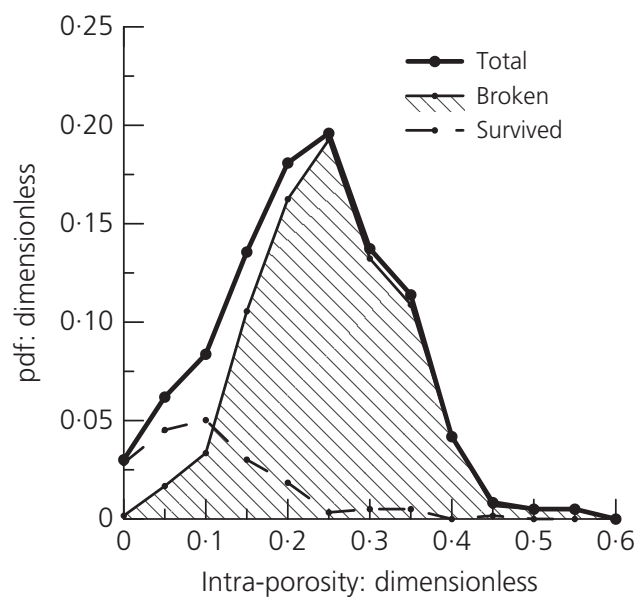

Fig. 6. Probability density function (pdf) of intra-porosity distribution, decomposed also between survived and broken particles

By observing the different amount of internal porosity from particle to particle, clearly visible in Fig. 1(a), and given the objective measurement of life expectancy for each particle described above, it is natural to wonder whether the most porous particles are the most likely to break. The intra-porosity of a particle is simply calculated as the volume of voids measured in the binary image within the volume of the label for the particle. Figure 6 plots the frequency distributions of particle intra-porosity, further decomposed into particles surviving until the end of the test, and particles breaking before the end of the test. The difference in the two probability distributions confirms a clear propensity for the particles with higher internal porosity to break on average.

\section{MICRO- TO MACRO-COMPARISONS}

Figure 7(a) shows the evolution of the number (Num) of intact particles normalised by the initial number of particles $\left(\mathrm{Num}_{0}\right)$, as measured in the tomo and the lab tests. In the lab tests, the number of surviving particles is empirically estimated by dividing the total volume retained on a given sieve by the volume of the sphere with diameter equal to the mean of the openings of the current and the previous sieves. The two trends are in relatively good agreement over the 


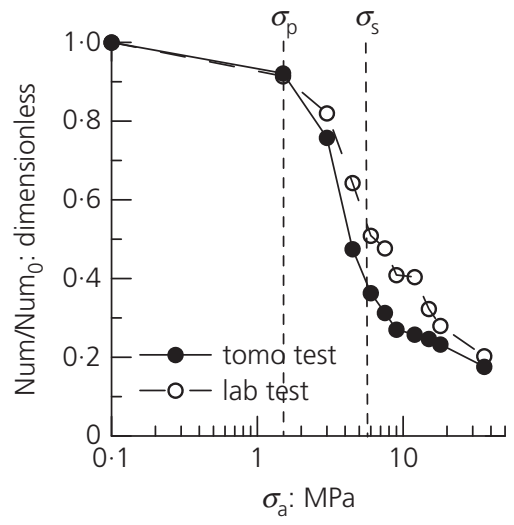

(a)

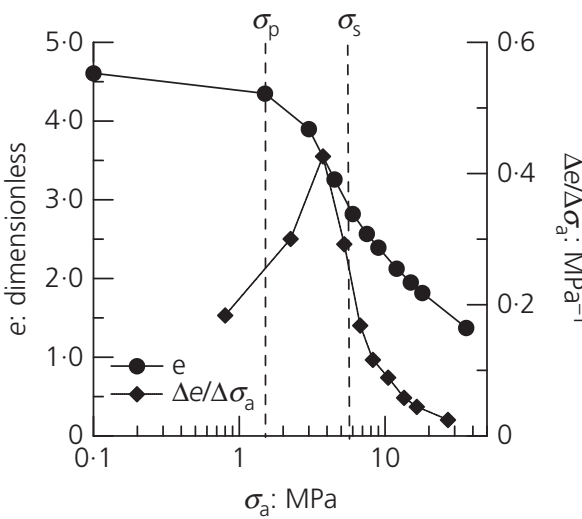

(b)

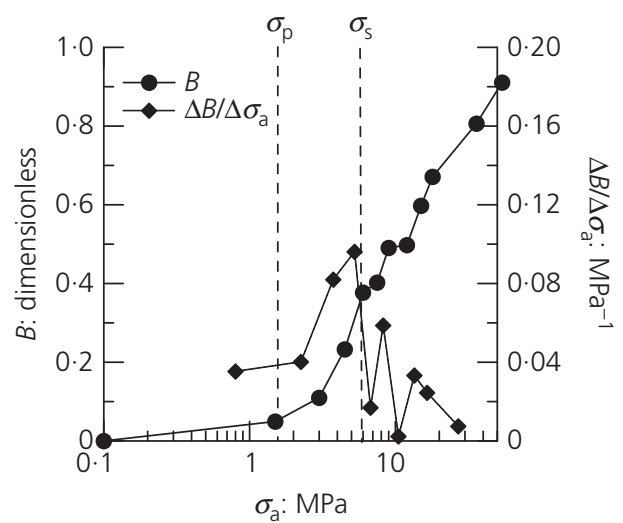

(c)

Fig. 7. (a) Evolution of number of intact particles comparing lab test with tomo test; (b) void ratio e and compressibility index in function of stress applied; (c) breakage and breakage rate trend in function of stress

whole stress range. After the yield stress, the number of particles surviving in the tomo test decreases faster than the lab tests, probably because the severe NCC threshold, compared to sieving, can flag a particle as broken even though its size may not have changed significantly (e.g. a chip off the surface). The local measurement of the evolution of the number of intact grains bears a striking resemblance to the macro-compressibility curve in Fig. 7(b) (plotted alongside the compression index $\Delta e_{\mathrm{i}} / \Delta \sigma_{\mathrm{i}}$ ). Furthermore, the evolution of the macroscopic compression index itself bears a striking resemblance to the evolution of the microscopic breakage rate $\Delta B_{\mathrm{i}} / \Delta \sigma_{\mathrm{i}}$ shown in Fig. 7(c) and plotted alongside $B$, computed according to the formulation of Einav (2007): $B=B_{\mathrm{t}} / B_{\mathrm{p}}$, where $B_{\mathrm{t}}$ and $B_{\mathrm{p}}$ are the total and the potential breakage, respectively. $B_{\mathrm{t}}$ is evaluated by integrating the area between the initial and the actual grading curve, and $B_{\mathrm{p}}$ is evaluated by integrating the area between the initial and the final grading curve in the semi-logarithmic plane, by assuming a power-law distribution for the final GSD $F(d)=\left(d / d_{\max }\right)^{0.52}$.

A distinct peak is observable in both rate quantities: the compressibility index $\Delta e_{\mathrm{i}} / \Delta \sigma_{\mathrm{i}}$ and the microscopic breakage rate $\Delta B_{\mathrm{i}} / \Delta \sigma_{\mathrm{i}}$, both close to the stress $\sigma_{\mathrm{s}}$ at the point of inflection.

\section{CONCLUSIONS}

Breakage of an artificial, porous granular material (LECA) has been studied in 1D compression with both standard laboratory techniques and in situ X-ray tomography during loading. X-ray tomography reveals, for example, that there is a wide distribution of internal porosity among LECA particles. For the first time, particle tracking is used to give an objective measurement of each particle's life expectancy.

A clear link between micro- and macro-scale quantities has been found: the evolution of number of surviving particles (micro) shows the same trend of the compressibility curve (macro). The peak in the rate of compressibility with respect to axial stress approximately coincides with the peak in the rate of particle breakage.

\section{REFERENCES}

Alonso, E. E., Olivella, S. \& Pinyol, N. M. (2005). A review of Beliche dam. Géotechnique 55, No. 4, 267-285, https://doi.org/ 10.1680/geot.2005.55.4.267.

Altuhafi, F. \& Coop, M. (2011). Changes to particle characteristics associated with the compression of sands. Géotechnique 61, No. 6, 459-471, https://doi.org/10.1680/geot.9.P.114.

Altuhafi, F. N., Coop, M. R. \& Georgiannou, V. N. (2016). Effect of particle shape on the mechanical properties of natural sands. J. Geotech. Geoenviron. Engng 142, No. 07, 145, https://doi.org/10.1061/(ASCE)GT.1943-5606.0001569.

Andò, E., Hall, S. A., Viggiani, G., Desrues, J. \& Bésuelle, P. (2012). Experimental micromechanics: grain-scale observation of sand deformation. Géotech. Lett. 2, No. 3, 107-112, https://doi.org/10.1680/geolett.12.00027.

Antonyuk, S., Tomas, J., Heinrich, S. \& Mörl, L. (2005). Breakage behaviour of spherical granulates by compression. Chem. Engng Sci. 60, No. 14, 4031-4044, https://doi.org/10.1016/j.ces.2005. 02.038 .

Casini, F., Viggiani, G. M. \& Springman, S. M. (2013). Breakage of an artificial crushable material under loading. Granular Matter 15, No. 5, 661-673, https://doi.org/10.1007/s10035013-0432-x.

Cil, M. B. \& Alshibli, K. (2014). 3D evolution of sand fracture under 1D compression. Géotechnique 64, No. 5, 351-364, https://doi.org/10.1680/geot.13.P.119. 
Cil, M. B. \& Alshibli, K. A. (2012). 3D assessment of fracture of sand particles using discrete element method. Géotech. Lett. 2, 161-166, http://dx.doi.org/10.1680/geolett.12.00024.

Colliat-Dangus, J. L., Desrues, J. \& Foray, P. (1988). Triaxial testing of granular soil under elevated cell pressure. In Advanced triaxial testing of soil and rock (eds R. T. Donaghe, R. C. Chaney and L. S. Marshall), pp. 290-310. West Conshohocken, PA, USA: ASTM International.

Coop, M. R., Sorensen, K. K., Bodas Freitas, T. \& Georgoutsos, G. (2004). Particle breakage during shearing of a carbonate sand. Géotechnique 54, No. 3, 157-163, https://doi.org/10.1680/ geot.2004.54.3.157.

Einav, I. (2007). Breakage mechanics - Part I: theory. J. Mech. Phys. Solids 55, No. 6, 1274-1297, https://doi.org/10.1016/j.jmps.2006. 11.003 .

Guida, G., Bartoli, M., Casini, F. \& Viggiani, G. M. (2016). Weibull distribution to describe grading evolution of materials with crushable grains. Procedia Engng 158, 75-80, https://doi.org/ 10.1016/j.proeng.2016.08.408

Hall, S., Bornert, M., Desrues, J., Pannier, Y., Lenoir, N., Viggiani, G. \& Bésuelle, P. (2010). Discrete and continuum experimental study of localised deformation in Hostun sand under triaxial compression using X-ray $\mu \mathrm{CT}$ and $3 \mathrm{D}$ digital image correlation. Géotechnique 60, No. 5, 315-322, https:// doi.org/10.1680/geot.2010.60.5.315.

Hardin, B. O. (1985). Crushing of soil particles. J. Geotech. Eng. 111, No. 10, 1177-1192.

Karatza, Z. (2017). A study of temporal and spatial evolution of deformation and breakage of dry granular materials using $X$-ray computed tomography and the discrete element method. PhD thesis, Ediburgh, Scotland: The University of Edinburgh.

Karatza, Z., Andò, E., Papanicolopulos, S. A., Ooi, J. \& Viggiani, G. (2018). Evolution of deformation and breakage in sand studied using X-ray tomography. Géotechnique 68, No. 2 , 107-117, http://dx.doi.org/10.1680/jgeot.16.P.208.
Kuwajima, K., Hyodo, M. \& Hyde, A. F. (2009). Pile bearing capacity factors and soil crushability. J. Geotech. Geoenviron. Engng 135, No. 7, 901-913, https://doi.org/10.1061/(ASCE)GT. 1943-5606.0000057.

Laterlite SpA (2017). Laterlite expanded clay - laterlite|laterlite. Milano, Italy: Laterlite SpA. See http://www.laterlite.com/ products/laterlite-expanded-clay/ (Accessed 28/10/2017).

Lewis, J. P. (1995). Fast normalized cross-correlation. Vision Interface 10, No. 1, 120-123.

McDowell, G. \& Bolton, M. (1998). On the micromechanics of crushable aggregates. Géotechnique 48, No. 5, 667-679, https://doi.org/10.1680/geot.2000.50.3.315.

Okubadejo, O., Karatza, Z., Andò, E., Bonnaud, L., Dalla Mura, M. \& Viggiani, G. (2017). Identification and tracking of particles undergoing progressive breakage under stress with 3D + t image analysis. In Proceedings ICTMS 2017, Lund, Sweden.

Todisco, M., Wang, W., Coop, M. \& Senetakis, K. (2017). Multiple contact compression tests on sand particles. Soils Found. 57, No. 1, 126-140.

Tudisco, E., Andò, E., Cailletaud, R. \& Hall, S. (2017). TomoWarp2: a local digital volume correlation code. Software $X \mathbf{6}, 267-270$.

Yang, Z., Jardine, R., Zhu, B., Foray, P. \& Tsuha, C. (2010). Sand grain crushing and interface shearing during displacement pile installation in sand. Géotechnique 60, No. 6, 469-482, https://doi.org/10.1680/geot.2010.60.6.469.

Yusufuku, N. \& Hyde, A. F. (1995). Pile end-bearing capacity in crushable sands. Géotechnique 45, No. 4, 663-676, https:// doi.org/10.1680/geot.1995.45.4.663.

Zhang, C., Einav, I. \& Nguyen, G. (2013). The end-bearing capacity of piles penetrating into crushable soils. Géotechnique 63, No. 5, 341-354, https://doi.org/10.1680/geot.11.P.117.

Zhao, B., Wang, J., Coop, M., Viggiani, G. \& Jiang, M. (2015). An investigation of single sand particle fracture using X-ray micro-tomography. Géotechnique 65, No. 8, 625-641, https://doi.org/10.1680/geot.4.P.157.

\section{HOW CAN YOU CONTRIBUTE?}

To discuss this paper, please submit up to 500 words to the editor at journals@ice.org.uk. Your contribution will be forwarded to the author(s) for a reply and, if considered appropriate by the editorial board, it will be published as a discussion in a future issue of the journal. 